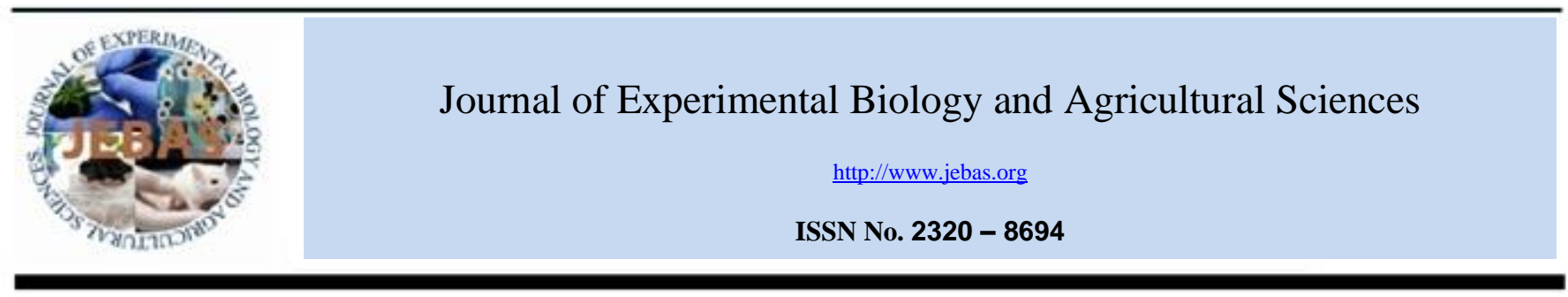

\title{
ANALYSIS OF LONG TERM IMPACT OF CYCLONIC DISASTER ‘AILA’ ON SOIL PROPERTIES AND PADDY YIELD OF SUNDARBANS, WEST BENGAL, INDIA
}

\author{
Sisir Kumar Si \\ Vivekananda Institute of Biotechnology, Sri Ramakrishna Ashram, P.O.-Nimpith Ashram, South 24-Parganas (Sundarbans), West Bengal, 743338
}

Received - November 06, 2015; Revision - November 28, 2015; Accepted - April 04, 2016

Available Online - April 25, 2016

DOI: http://dx.doi.org/10.18006/2016.4(2).142.148

\begin{abstract}
KEYWORDS
Aila

Cyclone

Land degradation

Paddy crop

Fertilizer

ABSTRACT

A field study was conducted to evaluate the long term impact of cyclonic disaster "Aila" on soil properties and paddy yield. Study was conducted during four consecutive rabi season started from 200910 onwards after the exposure of Aila at three highly Aila affected regions of Sundarbans viz Achintanagar (Patharprotima block), Kuemuri (Patharprotima block) and Shyamnagar (Kultali block) villages. Results of the study were compared to the adjoined non Aila affected area after soil test based fertilizer application (STNPK). Results of study revealed that Aila degraded the quality of paddy cultivation land by increasing EC $3 \mathrm{dSm}^{-1}$, ESP 18 and 2 to 2.7 times available iron over non Aila affected area along with completely failure of paddy production (average yield $0.45 \mathrm{t} / \mathrm{ha}$ ) in 2009-10 season. Results of next consecutive three seasons revealed that soil $\mathrm{pH}$, EC, ESP is improved and consequently paddy yield also increased naturally as compare to the yield of previous years in Aila affected area as well as yield of non Aila affected area in three villages. After third year of Aila occurrence, it was reported that paddy yield increase average $14 \%$ on application of extra $25 \% \mathrm{P}_{2} \mathrm{O}_{5}$, average $8 \%$ on application of extra $25 \% \mathrm{~K}_{2} \mathrm{O}$ and average $15 \%$ on application of extra $25 \%$ NPK over STNPK (Soil test based NPK dose)treatment. These fertilizer treatments ultimately made yield gap between Alia affected and non Aila affected area after third year of Aila occurrence. This is perhaps due to extra $\mathrm{P}_{2} \mathrm{O}_{5}$ fulfilled the $\mathrm{P}$ requirement of paddy in Fe rich Aila affected soils and at the same time extra $\mathrm{K}_{2} \mathrm{O}$ increased availability of $\mathrm{K}$ to paddy by maintaining the activity ratio of $\mathrm{K} / \sqrt{ }(\mathrm{Ca}+\mathrm{Mg})$ in saline environment of Aila affected areas.
\end{abstract}

* Corresponding author

E-mail: sisirkrsi@gmail.com (Si SK)

Peer review under responsibility of Journal of Experimental Biology and Agricultural Sciences.

Production and Hosting by Horizon Publisher India [HPI] (http://www.horizonpublisherindia.in/).

All rights reserved.
All the article published by Journal of Experimental Biology and Agricultural Sciences is licensed under a Creative Commons Attribution-NonCommercial 4.0

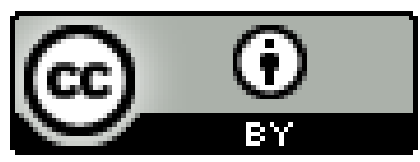
International License Based on a work at www.jebas.org. 


\section{Introduction}

Salinity is an important index of low soil quality reducing crop production. The amount of salt that is to accumulate is a function of water quality (Ayers \& Westcot, 1985) and evapotranspiration (Abrol, 1982). In arid and semi-arid regions, high rates of evapotranspiration and low rainfall can result in large amounts of salt accumulation near the soil surface. Whereas irrigated agriculture using saline water and ingression of sea water in land can lead to salt accumulation in soil profile, reduction in yield and deterioration in soil resource. Several researchers such as Feizi, 1993 and GarciaSanchez et al., 2003 reported advantageous effects of leaching by irrigation as well as rain water on improvement of soil salinity and crop yield.

Soil of Sundarban has been affected by different types of salt; characterization and distribution of soil in Sundarban coastal area was earlier described by Bandyapadhyay \& Sarkar, 1987; Bandyapadhyay et al., 2001 and Bandyapadhyay et al., 2003. These soils are highly acidic as well as saline in nature (Yadav et al., 1979) and it was formed from the gangetic alluvium due to the accumulation of sulphide materials of inter-tidal sediments. Acidic and saline natures are characteristics of such soils and play a critical role in the nutrient uptake, which needs to be assessed for judicious and efficient management of sustainable agriculture.
The nature's fury 'Aila' in the form of massive sea tidal waves on $25^{\text {th }}$ May, 2009 created devastation not only in terms of animal lives and loss of infrastructure in coastal Sundarban, but it also caused complete submergence of adjoining agricultural fields and rendered the soil and water resources salt affected. The cultivated land in coastal Sundarban is situated in low lying areas where drainage is often difficult due to very low slope gradient. Sea water ingression at the time of Aila led to stagnation situations in the agricultural land of Sundarban and this situation varies according to areas; in some area it was purely temporary and receded after temporary stagnation while in some are it stayed for long time and land remained stagnation with sea water for long time.

It was reported that this type of cyclones completely affect the agricultural production and in the passage of next few years farmers faced poor soil health conditions and this thing hampered crop production. Hence, there was an emergent need to assess the changes of soil characteristics and search suitable ways to reverse the degradation processes through optimal soil management measures. Therefore, present study has been undertaken to find out the impact of Aila on the characteristic of Achintanagar (Patharprotima block), Kuemuri (Patharprotima block) and Shyamnagar (Kultali block) area soil and rice yield. Furthermore, study also investigated to effect of fertilization (types and dose of fertilizers) on the retention and regaining of the soil quality and in improvement of the rice production.

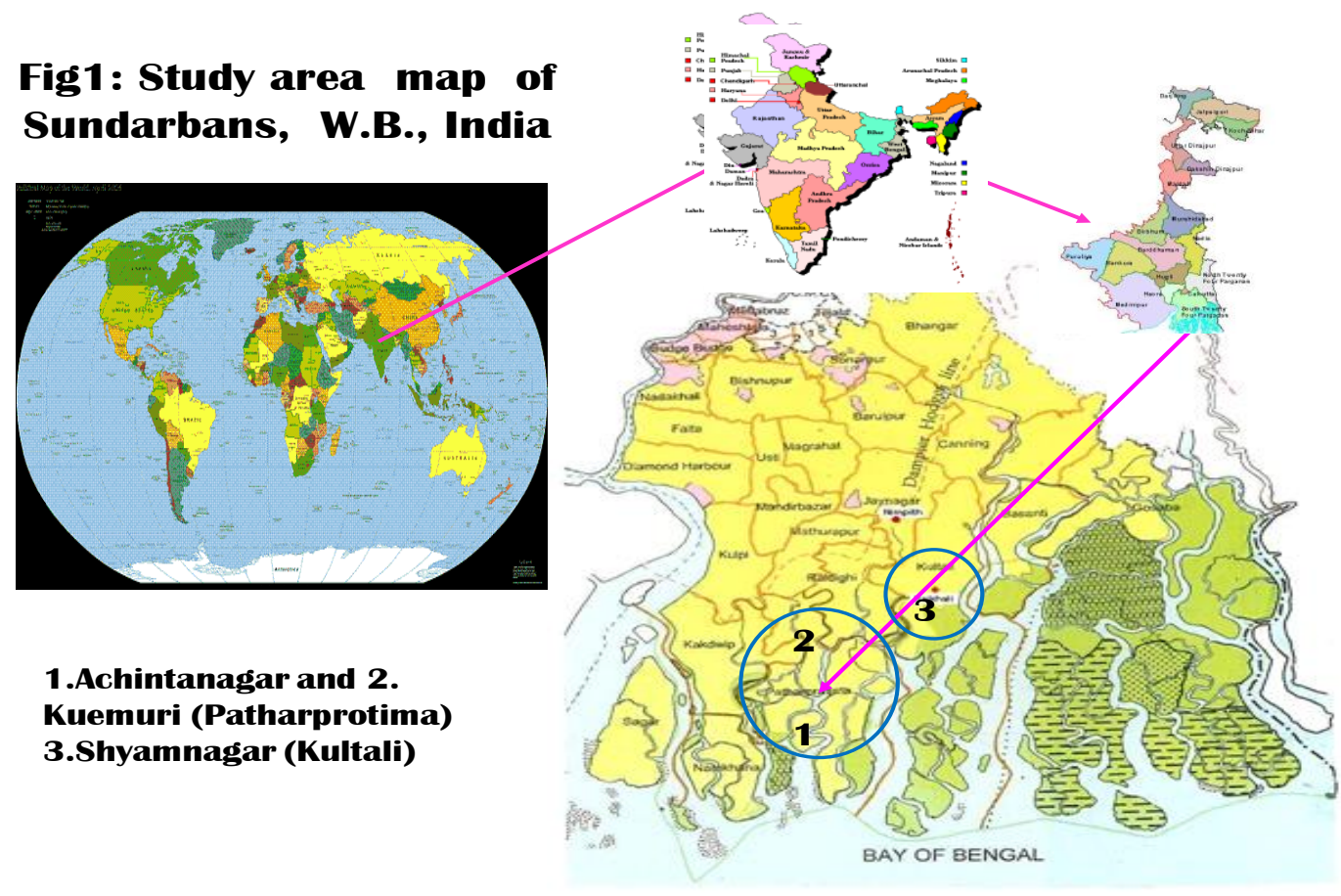

Figure 1 Study area map of sunderbans, W.B. India. 
2 Materials and Methods

With a view to the above objectives, collection and analysis of soil samples along with field studies of boro paddy (Lal Minikit, WGL 20471) were undertaken from selected Aila affected and non Aila affected area of three villages in Sundarbans (lies between longitude $88^{0} 10^{\prime} \mathrm{E}-89^{0} 51^{\prime} \mathrm{E}$, latitude $21^{0} 31^{\prime} \mathrm{N}-22^{0} 30^{\prime} \mathrm{N}$ ) viz. Achintanagar (Patharprotima block), Kuemuri (Patharprotima block) and Shyamnagar (Kultali block) in south 24 Parganas district, West Bengal (Figure. 1). Ten farmers of each Aila affected area and adjoined non Aila affected area in the aforesaid three villages were selected for present study. Surface soil samples (0-15 $\mathrm{cm})$ were collected from farmers' fields of each village covering entirely three different Aila affected areas and adjoined non Aila affected areas. Soil samples were air-dried, ground and pass through $2 \mathrm{~mm}$ sieve. Soil properties viz., $\mathrm{pH}$ (1:2), EC (1:2) soil: water ratio and organic carbon were determined as par the procedure giving by Jackson, 1973 and Walkley \& Black's method (Black, 1965). The ESP value was calculated by determination of cation exchange capacity (CEC) of the soil by extracting with neutral $1 \mathrm{~N} \mathrm{NH}_{4} \mathrm{OAc}$ solution and exchangeable sodium by flame photometer using standard laboratory methods (Page, 1986).

Available $\mathrm{Fe}$ was determined by Atomic Absorption Spectrometric (AAS) technique using DTPA extraction. Yield of boro paddy (2009-10) of selected farmers were recorded separately. Similarly next consecutive three years of Aila occurrence, soil test based fertilizer application and same agronomic management, analytical soil data as well as paddy yield (Lal Minikit) were recorded. After the third year of Aila occurrence, to study the yield gap between Aila affected and non Aila affected areas, selected farmer's fields were divided into five equal plots of approximate size $133 \mathrm{~m}^{2}$ for application of five fertilizer treatments viz soil test based recommended $100 \%$ NPK dosed for boro paddy ( STNPK) ; STNPK + Extra $25 \%$ nitrogen ( STNPK $+25 \% \mathrm{~N}$ ); STNPK + Extra 25\% phosphate( $\left.\mathrm{STNPK}+25 \% \mathrm{P}_{2} \mathrm{O}_{5}\right)$; STNPK + Extra 25\% potash( STNPK+ 25\% $\mathrm{K}_{2} \mathrm{O}$ ) and STNPK+ Extra 25\% nitrogen, phosphate and potash( STNPK $+25 \%$ NPK) as recommended by Ali, 2005 and boro paddy yields of the five plots of each farmers of Aila affected and non affected area of three villages are recorded.

The data are presented statistically and relative productivity percentage of crops is calculated as Average Paddy

Maximum average paddy yield of non Aila affected areas

\section{Results and Discussion}

The value of selected soil characteristics viz. $\mathrm{pH}, \mathrm{EC}, \mathrm{OC}, \mathrm{ESP}$ and available $\mathrm{Fe}$ in Aila affected and non Aila affected Achintanagar, Kuemuri and Shyamnagar villages of Sundarban was recorded for 2009-10 and three consecutive years after Aila, results of these characteristics are presented in table 1 . The table 1 revealed that the overall soil $\mathrm{pH}$ of non Aila affected Achintanagar is acidic in nature with an average $\mathrm{pH}$ value 5.24 where as nature of soil $\mathrm{pH}$ of Aila affected Achintanagar is neutral with an average $\mathrm{pH}$ value 6.93. It may be due to accumulation of carbonate and bicarbonate salt from sea water at the time of Aila occurrence.

Table 1 Soil properties of Achintanagar, Kuemuri and Shamnagar village in Sundarban after Aila (value given in table is mean of ten replicates)

\begin{tabular}{|c|c|c|c|c|c|}
\hline Time interval & pH & $\mathrm{EC} \mathrm{dSm}^{-1}$ & ESP & OC $(\%)$ & $\mathrm{Fe}(\mathrm{mg} / \mathrm{kg})$ \\
\hline \multicolumn{6}{|c|}{ Achintanagar } \\
\hline Non Aila Affected area & $5.24 \pm 0.49$ & $1.23 \pm 0.46$ & $10.40 \pm 3.82$ & $0.40 \pm 0.13$ & $37.97 \pm 25.23$ \\
\hline Aila Affected area & $6.93 \pm 1.04$ & $11.02 \pm 2.56$ & $30.72 \pm 7.86$ & $0.46 \pm 0.20$ & $101.64 \pm 167.82$ \\
\hline $1^{\text {st }}$. Year after Aila & $6.7 \pm 0.83$ & $2.40 \pm 0.69$ & $17.37 \pm 6.78$ & $0.46 \pm 0.19$ & $102.29 \pm 171.47$ \\
\hline $2^{\text {nd }}$. Year after Aila & $6.51 \pm 0.77$ & $137 \pm 0.52$ & $12.49 \pm 4.75$ & $0.44 \pm 0.19$ & $99.72 \pm 164.79$ \\
\hline $3^{\text {rd }}$. Year after Aila & $6.55 \pm 0.69$ & $1.30 \pm 0.38$ & $12.00 \pm 3.00$ & $0.42 \pm 0.16$ & $100.51 \pm 161.41$ \\
\hline \multicolumn{6}{|c|}{ Kuemuri } \\
\hline Non Aila Affected area & $5.36 \pm 0.65$ & $1.36 \pm 0.68$ & $8.81 \pm 2.89$ & $0.43 \pm 0.11$ & $46.69 \pm 26.64$ \\
\hline Aila Affected area & $6.63 \pm 1.05$ & $12.13 \pm 3.99$ & $31.75 \pm 8.74$ & $0.57 \pm 0.23$ & $126.42 \pm 207.63$ \\
\hline $1^{\text {st }}$. Year after Aila & $6.47 \pm 0.93$ & $2.61 \pm 0.96$ & $17.26 \pm 7.52$ & $0.55 \pm 0.20$ & $124.21 \pm 204.23$ \\
\hline $2^{\text {nd }}$. Year after Aila & $6.34 \pm 0.69$ & $1.66 \pm 0.91$ & $12.46 \pm 6.17$ & $0.53 \pm 0.21$ & $123.21 \pm 204.32$ \\
\hline $3^{\text {rd }}$. Year after Aila & $6.39 \pm 0.71$ & $1.57 \pm 0.79$ & $11.95 \pm 3.49$ & $0.49 \pm 0.16$ & $121.35 \pm 201.68$ \\
\hline \multicolumn{6}{|c|}{ Shyamnagar } \\
\hline Non Aila Affected area & $5.37 \pm 0.55$ & $1.19 \pm 0.89$ & $11.69 \pm 1.89$ & $0.43 \pm 0.13$ & $32.66 \pm 22.97$ \\
\hline Aila Affected area & $6.98 \pm 0.93$ & $10.33 \pm 4.38$ & $40.71 \pm 8.09$ & $0.45 \pm 0.20$ & $59.10 \pm 84.92$ \\
\hline $1^{\text {st }}$. Year after Aila & $6.71 \pm 0.72$ & $2.19 \pm 1.17$ & $24.59 \pm 5.72$ & $0.44 \pm 0.19$ & $58.61 \pm 82.52$ \\
\hline $2^{\text {nd }}$. Year after Aila & $6.51 \pm 0.52$ & $1.43 \pm 1.12$ & $18.66 \pm 5.19$ & $0.42 \pm 0.18$ & $56.84 \pm 80.01$ \\
\hline $3^{\text {rd }}$. Year after Aila & $6.60 \pm 0.48$ & $1.34 \pm 0.80$ & $17.59 \pm 3.90$ & $0.39 \pm 0.15$ & $55.73 \pm 76.89$ \\
\hline $\mathrm{CD}(\mathrm{P}=0.05$ & 0.127 & 0.496 & 1.96 & & 17.22 \\
\hline
\end{tabular}

Value given in table is mean of ten replicates; value give after \pm represent $\mathrm{SD}$ 
It is also reported that after first year, in successive years of Aila, the soil $\mathrm{pH}$ has slowly come down. The soil $\mathrm{pH}$ of Aila affected Kuemuri and Shyamnagar was also showing similar trends to Achintanagar with respect to non Aila affected areas. The average soil EC of non Aila affected Achintanagar is 1.23 $\mathrm{dSm}^{-1}$ and the average values of ESP is 10.40 (Table 1). While the average EC $11.02 \mathrm{dSm}^{-1}$ and ESP 30.72 is attained after Aila occurrence at Achintanagar. With passage of first, second and third year after Aila, the mean EC value come down in 2.4 $\mathrm{dSm}^{-1}, 1.37 \mathrm{dSm}^{-1}$ and $1.30 \mathrm{dSm}^{-1}$ respectively Whereas the mean ESP value come down in 17.37, 12.49 and 12.00 respectively at Achintanagar. The reason of improvement of soil salinity on passage of time is the effect of salt leaching i.e. desalinization by rainwater infiltration (Mostafazdeh-Fard et al., 2008). The same trend of EC and ESP values are observed in Kuemuri and Shamnagar village at different time intervals with respect to non Aila affected area.

The average OC percentage of the non Aila affected Achintanagar soils is recorded 0.40 whereas in Aila affected area, it is 0.46 . It is also found a decreasing tendency of means $\mathrm{OC}$ values after passing of first, second and third year may be due to effects of rain water leaching as well as land use for paddy (Kolahchi \& Jalali ,2007). Similar patterns are also observed in others two Aila affected areas (Table 1). Analysis of the results presented in the table 1, suggested that about $40 \%$ samples are in safe limit (ESP <10) and 60\% samples are moderate safe limit (ESP 10-18) in non Aila affected area of three localities. Whereas after Aila only 3\% samples are moderately safe limits (ESP 10-18) and the rest are in higher ESP (ESP>18) which are unsafe for cultivation (Richards , 1954). The passage of first, second and third year after Aila $64 \%, 40 \%$ and $23 \%$ samples became unsafe (ESP >18) respectively in the aforesaid areas. It is also found that about
$3 \%$ samples are at injury level $\left(>3 \mathrm{dSm}^{-1}\right)$ in non Aila affected areas whereas in Aila affected areas $100 \%$ samples are at injury level with respect to EC values (Ali, 2005). After first, second and third year of Aila the injury level have become $30 \%, 10 \%$ and $3 \%$ samples respectively. On encountering the whole three villages, the status of soil $\mathrm{pH}$ are $53 \%$ samples are strong acidic $(\mathrm{pH}<5.5), 37 \%$ samples are moderately acidic (pH 5.5- 6.0) and 10\% slightly acidic (pH 6.0-6.5) in non Aila affected area, whereas in Aila affected areas the status of soil $\mathrm{pH}$ are $30 \%$ alkaline $(\mathrm{pH}>7.5) 26 \%$ neutral $(\mathrm{pH} 6.5-7.5), 20 \%$ slightly acidic (pH 6.0-6.5),20\% moderate acidity (pH 5.5-6.0) and rest are strong acidic. After first year of Aila occurrence the $\mathrm{pH}$ status are almost unchanged but in second and third year about $40 \%$ and $54 \%$ samples have neutral $(\mathrm{pH}$ 6.5-7.5) and rest soils are slightly to moderate acidity ( $\mathrm{pH} \mathrm{5.5-6.5).}$ There are no soils in alkaline range $(\mathrm{pH}>7.5)$ in second and third year after Aila.

On the other hand, $73 \%$ collected samples shows presence of low OC while $27 \%$ samples shows the presence of medium OC in non Aila affected areas, whereas in Aila affected areas, the status of OC had became 53\% low, 27\% medium and 20\% high. These changes in the status of OC may be due to deposition of fresh organic matter during the flood. After first year of Aila occurrence the OC status are unchanged but in second year only $13 \%$ OC are high level (OC \% >0.75) and in third year the OC status are almost equal to non Aila affected areas i.e. $64 \%$ low and $36 \%$ medium. Higher analytical values of OC leads the blackish coloration of soils in some fields after Aila which may be resulted by the dissolution and dispersion of organic matter at high $\mathrm{pH}$ and $\operatorname{ESP}($ Table 1), which is also the agreement of the observation of Bandyapadhyay et al. (2001).

Table 2 Yield of boro paddy at farmers' field in Sundarban after Aila

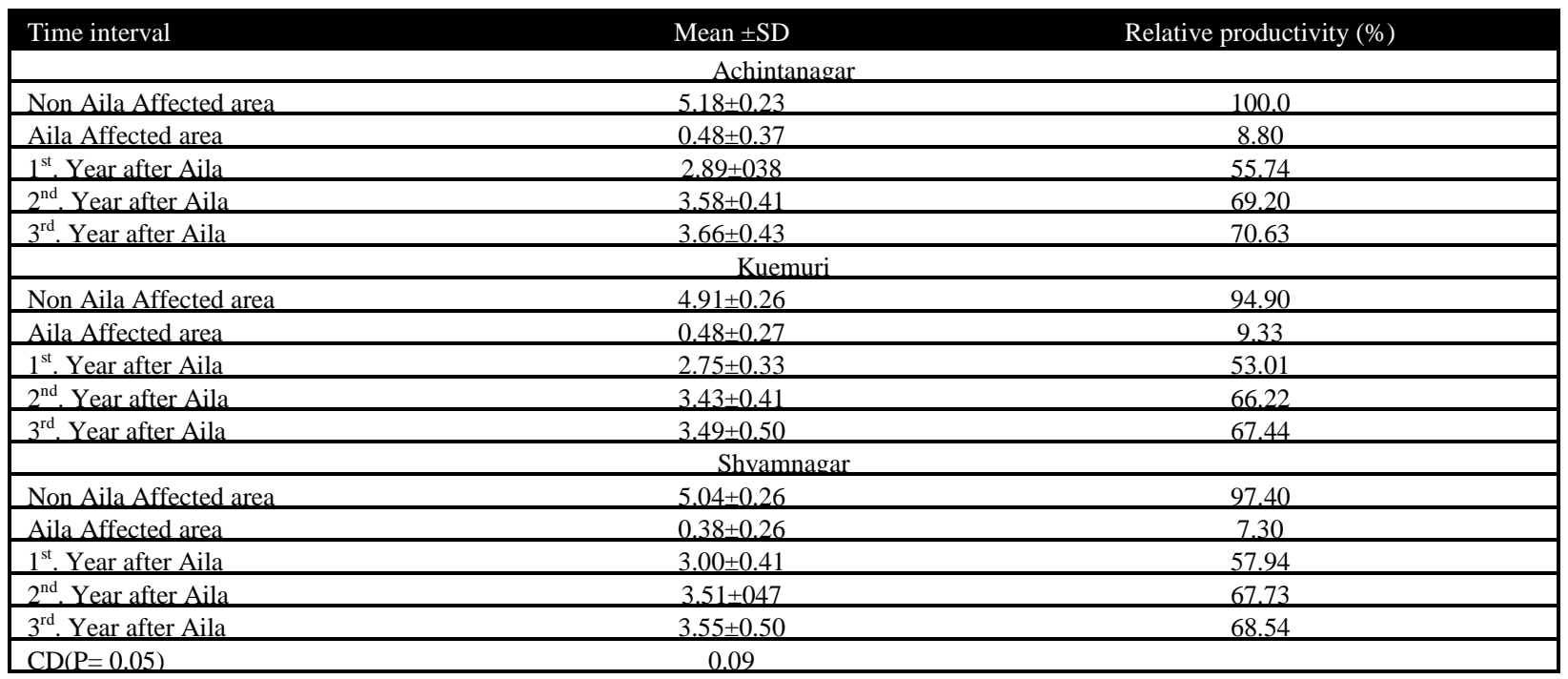

Value given in table is mean of ten replicates 
Table 3 Yield of boro paddy on different fertilizer treatments at farmers' field in Sundarban after third years' of Aila occurrence

\begin{tabular}{|c|c|c|}
\hline Different treatments & Mean \pm SD & Relative productivity (\%) \\
\hline \multicolumn{3}{|c|}{ Achintanagar } \\
\hline STNPK & $3.66 \pm 0.43$ & 70.63 \\
\hline STNPK+ 25\% N & $3.71 \pm 0.46$ & 71.73 \\
\hline $\mathrm{STNPK}+25 \% \mathrm{P}_{2} \mathrm{O}_{5}$ & $4.29 \pm 0.36$ & 82.85 \\
\hline STNPK+ $25 \% \quad \mathrm{~K}_{2} \mathrm{O}$ & $3.93 \pm 0.45$ & 75.84 \\
\hline STNPK+ 25\% NPK & $4.42 \pm 0.46$ & 85.40 \\
\hline \multicolumn{3}{|c|}{ Kuemuri } \\
\hline STNPK & $3.49 \pm 0.50$ & 67.44 \\
\hline STNPK $+25 \% \mathrm{~N}$ & $3.52 \pm 0.36$ & 67.90 \\
\hline $\mathrm{STNPK}+25 \% \mathrm{P}_{2} \mathrm{O}_{5}$ & $4.39 \pm 0.35$ & 84.70 \\
\hline STNPK+ 25\% $\quad \mathrm{K}_{2} \mathrm{O}$ & $4.06 \pm 0.45$ & 78.33 \\
\hline STNPK+ 25\% NPK & $4.52 \pm 0.41$ & 87.20 \\
\hline \multicolumn{3}{|c|}{ Shyamnagar } \\
\hline STNPK & $3.55 \pm 0.50$ & 68.54 \\
\hline STNPK+ 25\% N & $3.60 \pm 0.45$ & 69.52 \\
\hline $\mathrm{STNPK}+25 \% \mathrm{P}_{2} \mathrm{O}_{5}$ & $4.26 \pm 0.40$ & 82.33 \\
\hline STNPK+ 25\% $\quad \mathrm{K}_{2} \mathrm{O}$ & $3.96 \pm 0.35$ & 76.54 \\
\hline STNPK+ $25 \%$ NPK & $4.37 \pm 0.53$ & 84.36 \\
\hline $\mathrm{CD}(\mathrm{P}=0.05)$ & 0.09 & \\
\hline
\end{tabular}

Whereas: STNPK (100\% NPK dosed for boro paddy); STNPK+ 25\% N (STNPK + Extra 25\% nitrogen); STNPK+ 25\% $\mathrm{P}_{2} \mathrm{O}_{5}(\mathrm{STNPK}+$ Extra 25\% phosphate);STNPK+ 25\% $\mathrm{K}_{2} \mathrm{O}(\mathrm{STNPK}+$ Extra $25 \%$ potash)and STNPK+ $25 \% \mathrm{NPK}(\mathrm{STNPK}+$ Extra $25 \%$ nitrogen, phosphate and potash).

The average DTPA-Fe content in three non Aila affected Achintanagar; Kuemuri and Shyamnagar villages are 37.97, 46.69 and $32.66 \mathrm{mg} / \mathrm{kg}$ (Table 1). Whereas in these three Aila affected villages the average $\mathrm{Fe}$ content increases remarkably and their values are 101.64, 126.42 and $59.10 \mathrm{mg} / \mathrm{kg}$ respectively. There is no remarkable change in average value of Fe with passage of first, second and third year after Aila.

The yield of boro paddy and their average value along with their relative productivity percentage in Aila affected and non Aila affected areas of Achintanagar; Kuemuri and Shyamnagar villages in consecutive four seasons are presented in table 2 . Considering total non Aila affected areas of three villages, the average yield of boro paddy lie between 4.91 and $5.18 \mathrm{t} / \mathrm{ha}$, whereas considering total Aila affected areas of three villages lie between 0.38 and $0.48 \mathrm{t} / \mathrm{ha}$. Next successive three boro seasons the average yield of total Aila affected areas of three villages have increased naturally and their average values lie between 2.75 and $3.00 \mathrm{t} / \mathrm{ha}$ in first year, 3.43 and $3.58 \mathrm{t} / \mathrm{ha}$ in second year, 3.49 and 3.66 t/ha in third year (Table 2) respectively.

Table 2 shows that the relative productivity percentage in three Aila affected villages and these are 8.80, 9.33 and 7.30. It is also observed that relative productivity percentage of boro paddy in total three Aila affected areas of three villages have been increased (ranged from 53.08 to 57.94) after first year of Aila occurrence. After passage of second and third years, the range became 66.22 to 69.20 and 67.44 to 70.63 respectively. Through the average paddy yield in third year increased slightly in compare to the yield of second year after Aila, yet there found a yield gap between Aila affected areas and non Aila affected areas after third year (Table 2). It may be due to the high concentration of iron and comparatively higher value of EC and ESP in compare to non Aila affected areas (Table 1) has still hampered the paddy production in Aila affected areas.

Based on five fertilizer treatments i.e. STNPK , STNPK+ 25\% $\mathrm{N}, \mathrm{STNPK}+25 \% \mathrm{P}_{2} \mathrm{O}_{5}, \mathrm{STNPK}+25 \% \mathrm{~K}_{2} \mathrm{O}$ and STNPK $+25 \%$ NPK in Aila affected areas of three Villages, the average paddy yield in rabi season, after third year of Aila are recorded in table 3. The Paddy yield of Aila affected Achintanagar, Kuemuri and Shyamnagar villages are remarkably increased of an average $4.29,4.39$ and $4.26 \mathrm{t} / \mathrm{ha}$ by application of STNPK+ $25 \% \mathrm{P}_{2} \mathrm{O}_{5}, 3.93,4.06$ and $3.96 \mathrm{t} / \mathrm{ha}$ by application of STNPK+ $25 \% \mathrm{~K}_{2} \mathrm{O}, 4.42,4.52$ and $4.37 \mathrm{t} / \mathrm{ha}$ by application of STNPK+ $25 \%$ NPK over the average yield 3.66, 3.49 and 3.55 t/ha based on STNPK treatment in three respective villages. On the other hand, STNPK $+25 \% \mathrm{~N}$ treatment increases slightly paddy yield of an average $3.71,3.52$ and 3.60 t/ha with respect to STNPK treatment in three respective villages.

Table 3 also shows that the relative productivity percentage $82.85,84.70,82.33$ on treatment STNPK $+25 \% \mathrm{P}_{2} \mathrm{O}_{5}$ and 85.40, 87.20, 84.36 on treatment STNPK+ 25\% NPK in Aila affected areas of Achintanagar, Kuemuri and Shyamnagar villages are very close to non Aila affected areas of respective three villages and simultaneously it is agreement with the same land suitability class for paddy according to Sys et al. (1993). From the results of five fertilizer treatments (Table 3), it may be said that recommended phosphate are less available to paddy perhaps due to high concentration of $\mathrm{Fe}$ in Aila affected 
soils (Adhikari \& Si, 1994) which fixed most of recommended phosphate. When extra phosphate over recommended dose is applied then paddy response and yield is increased. On the other hand, saline environment of Aila affected soils with high amount of $\mathrm{Ca}$ and $\mathrm{Mg}$ decrease the activity ratio $\mathrm{K} / \sqrt{ }(\mathrm{Ca}+$ $\mathrm{Mg}$ ).So, plant face problem to uptake available $\mathrm{K}$ (Joshi, 1992). Extra $\mathrm{K}$ over recommended dose (STNPK+ 25\% $\left.\mathrm{K}_{2} \mathrm{O}\right)$ lead increases the activity ratio $\mathrm{K} / \sqrt{ }(\mathrm{Ca}+\mathrm{Mg})$ and consequently increases the uptake of available $\mathrm{K}$ as well as significantly paddy yield.

\section{Conclusions}

Present study shows that cyclone Aila affected the lands of Sundarban by making various types of degradation like high salinity, alkalinity and $\mathrm{Fe}$ content and it resulted poor crop performance. Result of study indicated that poor growth of paddy is due to high salinity ( $>3 \mathrm{dSm}^{-1}$ ) and high alkalinity (ESP $>18$ ) which gradually reduced by leaching with rain water in passage of consecutive three years. The yield of boro paddy is further improved by application of extra phosphate and extra potash over soil test based fertilizer dose that enhance phosphorous and potassium availability to paddy in Fe richer saline environment.

\section{Acknowledgement}

The author is grateful to Swami Sadananda Maharaj, Chairman, Sri R.K. Ashram, Nimpith, Dr. B. K. Datta, Director, Vivekananda Institute of Biotechnology, Nimpith and Prof. A. K. Sarkar, Former Professor and Head (Soil Science) and Dean Faculty of Agriculture, Birsa Agricultural University, Ranchi, Jharkhand for necessary help and continuous encouragement.

\section{Conflict of interest}

Authors would hereby like to declare that there is no conflict of interests that could possibly arise.

\section{References}

Abrol IP (1982) Reclamation and management of salt affected soils. Review of soil research in India, Part II, Trans. $12^{\text {th }}$ International Congress Soil Science, New Delhi.

Ali SK (2005) Fertilizer recommendation for principal crops and cropping sequences of West Bengal, Booklet no. 1, Department of Agriculture, Government of West Bengal, 4-5.

Ayers RS, Westcot DW (1985) Water quality for agriculture, irrigation and drainage, Paper no. 29, FAO, Rome.

Adhikari M, Si SK (1994) Distribution of inorganic phosphorous fractions in some soils of West Bengal. Journal Indian Society of Soil Science 42:459-461.
Bandyapadhyay AK, Sarkar D (1987) Occurrence of acid saline soils in coastal area in Sundarban area of West Bengal. Journal Indian Society of Soil Science 35: 42-44.

Bandyapadhyay BK, Maji B, Sen HS, Tyagi NK (2003) Coastal saline soils of West Bengal, Their nature, distribution and characteristics, CSSRI Regional Research Station, Bull no. 1 West Bengal, India, 62.

Bandyapadhyay BK, Maji B, Sen HS, Yadav JSP (2001) Saline and alkaline soils and their management, ISCAR Monograph no. 1, Indian Society of Coastal Agricultural. Research, West Bengal, India.

Black CA (1965) Methods of soil analysis, Part 1 \& 2, American Society of Agronomy, Inc. Madison, Wisconsin, USA.

Feizi M (1993) Investigation of the effects of water quality and quantity on soil desalinization of Rudasht region of Isfahan province, Journal Soil Water 8:16-34.

Garcia-Sanchez F, Carvajal M, Porras I, Botia P, Martinez V (2003) Effects of salinity and rate of irrigation on yield, fruit quality and mineral composition of lemon. European Journal Agronomy 19: 427-437. doi:10.1016/S1161-0301(02)00138-7.

Joshi DC (1992) Relationship between the quantity and intensity parameters of labile potassium in arid sols of Indian desert. Journal Indian Society of Soil Science 40: 431-442

Jackson ML (1973) Soil chemical analysis. Prentice Hall of India Pvt. Ltd., New Delhi.

Kolahchi Z, Jalali M (2007) Effect of water quality on the leaching of potassium from sandy soil. Journal Arid Environment 68:624-639. doi:10.1016/j.jaridenv.2006.06.010.

Mostafazadeh-Fard B, Haydarpour M, Aghakhani A, Feizi M (2008) Effects of leaching on soil desalinization for wheat crop in an arid region. Journal Plant Soil Environment 54:20-29

Page AL (1986) Methods of soil analysis, Part II: Soil chemical analysis. American Society of Agronomy, Inc. Madison, Wisconsin, USA.

Richards LA (1954) Diagnosis and improvement of salinealkaline soils, United State Department of Agriculture, Agriculture Hand Book, 60.

Sys Ir C, VanRanst E, Debaveye Ir J, Beernaert F (1993) Land Evaluation, Part II, Crop requirements, Agricultural publications no 7, General administration for development cooperation place du champ de mars 5 bte 57-1050, Brussels, Belgium, 117-124. 
Yadav JSP, Bandyapadhyay AK, Rao KVGK, Sinha TW,

Biswas CR (1979) Bulletin Central Soil Salinity Research Institute 5: 34 . 